\title{
Incorporation of silver (I) ions within zeolite cavities and their photocatalytic reactivity for the decomposition of $\mathrm{N}_{2} \mathrm{O}$ into $\mathrm{N}_{2}$ and $\mathrm{O}_{2}$
}

\author{
Woo-Sung Ju, Masaya Matsuoka, and Masakazu Anpo ${ }^{\dagger}$ \\ Department of Applied Chemistry, Graduate School of Engineering, Osaka Prefecture University, \\ 1-1 Gakuen-cho, Sakai, Osaka 599-8531, Japan
}

\begin{abstract}
Ag}^{+} / \mathrm{ZSM}-5$ catalysts were prepared by an ion-exchange method. UV-irradiation of the $\mathrm{Ag}^{+} / \mathrm{ZSM}^{-}$ 5 catalysts in the presence of $\mathrm{N}_{2} \mathrm{O}$ led to the photocatalytic decomposition of $\mathrm{N}_{2} \mathrm{O}$ into $\mathrm{N}_{2}$ and $\mathrm{O}_{2}$ at $298 \mathrm{~K}$. Investigations of the effective wavelength of the irradiated UV-light for the reaction as well as the in-situ characterization of the catalysts by means of UV-Vis, photoluminescence and FT-IR spectroscopies revealed that the photoexcitation of the $\mathrm{Ag}^{+}-\mathrm{N}_{2} \mathrm{O}$ complexes formed between gaseous $\mathrm{N}_{2} \mathrm{O}$ and the isolated $\mathrm{Ag}^{+}$ ions exchanged within the zeolite cavities plays a significant role in the reaction.
\end{abstract}

\section{INTRODUCTION}

It has been reported that silver (I) ion-exchanged zeolites exhibit unique and high catalytic reactivities for $\mathrm{De}-\mathrm{NO}_{x}$ reactions such as the selective catalytic reduction of $\mathrm{NO}_{x}$ with hydrocarbons or dimethylether and the direct photocatalytic decomposition of NO [1-6]. However, the reactivity of $\mathrm{Ag}^{+} /$zeolites with $\mathrm{N}_{2} \mathrm{O}$, especially under UV-irradiation, has not yet been fully investigated. In the present study, highly dispersed $\mathrm{Ag}^{+}$ions as well as their photocatalytic reactivity for the decomposition of $\mathrm{N}_{2} \mathrm{O}$ at ambient temperatures have been investigated by means of insitu UV-Vis, photoluminescence, FT-IR measurements, along with an analysis of the reaction products.

\section{EXPERIMENTAL}

$\mathrm{H}^{+} / \mathrm{ZSM}-5\left(\mathrm{SiO}_{2} / \mathrm{Al}_{2} \mathrm{O}_{3}=23.8\right)$ type of zeolite was used as the parent zeolite. $\mathrm{Ag}^{+} / \mathrm{ZSM}-5$ catalysts having different Ag content were prepared by a conventional ion-exchange of the corresponding $\mathrm{H}^{+} / \mathrm{ZSM}-5$ with a dilute $\mathrm{AgNO}_{3}$ solution at $298 \mathrm{~K}$ for $24 \mathrm{~h}$. After the ion-exchange, the samples were washed with distilled water and dried in air at $373 \mathrm{~K}$. The silver loadings of the $\mathrm{Ag}^{+} / \mathrm{ZSM}-5$ catalysts were determined to be $0.5 \sim$ $3.9 \mathrm{wt} \%$ by an atomic absorption spectrometer.

Prior to spectroscopic and photocatalytic reactivity measurements, samples were degassed at $673 \mathrm{~K}$, calcined at $673 \mathrm{~K}$ in the presence of 20 Torr of $\mathrm{O}_{2}$ for $1 \mathrm{~h}$, and then finally evacuated under a vacuum of $<10^{-5}$ Torr at $473 \mathrm{~K}$ for $1 \mathrm{~h}$. Photocatalytic reactions were carried out with the catalysts $(50 \mathrm{mg}$ ) in a conventional closed system at $298 \mathrm{~K}$ with a flat transparent quartz window using a high pressure mercury lamp through a water filter. UV-cut filter $(\lambda>250 \mathrm{~nm})$ was

† E-mail: anpo@ok.chem.osakafu-u.ac.jp used to examine the effect of the irradiation wavelength upon the reaction. The reaction products, nitrogen and oxygen, were analyzed by gas chromatography.

\section{RESULTS AND DISCUSSION}

The coordination state of the $\mathrm{Ag}^{+}$ion species exchanged within the zeolite was investigated by UV-Vis measurements. Figure 1 shows the UV-Vis spectra of $\mathrm{Ag}^{+} / \mathrm{ZSM}-5$ with various content of $\mathrm{Ag}$ ion obtained after pretreatment. Only a sharp absorption band at around $190 \mathrm{~nm}$ due to the $4 d^{10} \rightarrow 4 d^{9} 5 s^{1}$ electronic transition of the isolated $\mathrm{Ag}^{+}$ion can be observed for $\mathrm{Ag}^{+} / \mathrm{ZSM}-5$ [7].

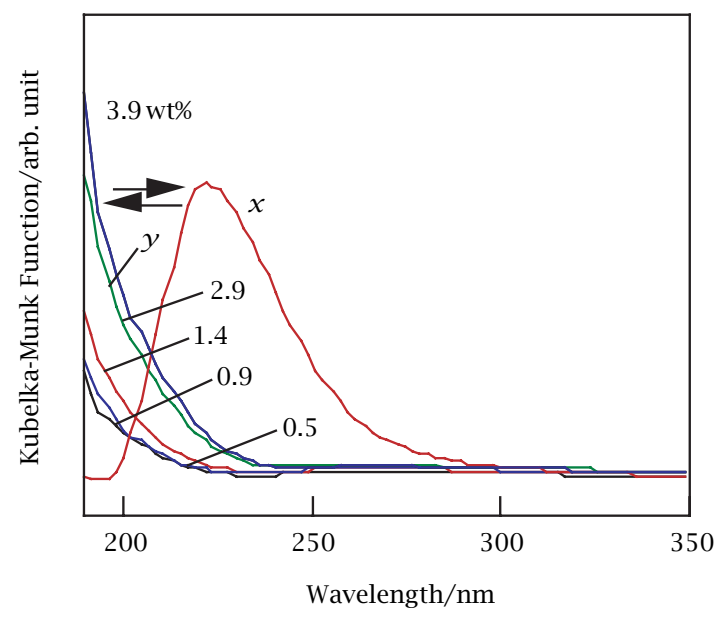

Figure 1. UV-Vis spectra of the $\mathrm{Ag}^{+} / Z S M-5$ with different $\mathrm{Ag}$ loadings and the effect of the addition of $\mathrm{N}_{2} \mathrm{O}$ on the $U V$-Vis spectrum of the $\mathrm{Ag}^{+} / Z S M-5$ (2.9) at $298 \mathrm{~K}$. (x) after the addition of $\mathrm{N}_{2} \mathrm{O} 1$ Torr. (y) after the degassing of $\mathrm{N}_{2} \mathrm{O}$ at $298 \mathrm{~K}$. 
On the other hand, the addition of nitrous oxide on $\mathrm{Ag}^{+} / \mathrm{ZSM}-5$ with a silver loading of $2.9 \%$ (denoted as $\mathrm{Ag}^{+} / \mathrm{ZSM}-5$ (2.9)) leads to the disappearance of the band at $190 \mathrm{~nm}$ and, simultaneously, the appearance of a new band at $220 \mathrm{~nm}$, which can be assigned to the $\mathrm{Ag}^{+}-\mathrm{N}_{2} \mathrm{O}$ complexes, while the evacuation of the system at $298 \mathrm{~K}$ leads to the complete restoration of the original absorption band. These results indicate that the addition of $\mathrm{N}_{2} \mathrm{O}$ results in the formation of $\mathrm{Ag}^{+}-\mathrm{N}_{2} \mathrm{O}$ complexes, which modify the coordination sphere and energy gap of the intraionic electronic transition of $\mathrm{Ag}^{+}\left(4 d^{10} \rightarrow 4 d^{9} 5 s^{1}\right)$, however, the adsorption of $\mathrm{N}_{2} \mathrm{O}$ on $\mathrm{Ag}^{+}$is weak and reversible.

The interaction of $\mathrm{N}_{2} \mathrm{O}$ with $\mathrm{Ag}^{+}$ion was investigated by means of FT-IR spectroscopy. As shown in Figure 2, the $\mathrm{Ag}^{+} / \mathrm{ZSM}-5$ (2.9) catalyst exhibits a specific FT-IR band at $2251 \mathrm{~cm}^{-1}$ in the presence of 1 Torr of $\mathrm{N}_{2} \mathrm{O}$, assigned to the asymmetric stretching mode of the adsorbed $\mathrm{N}_{2} \mathrm{O}$ [8], whereas the position of the band $\left(2251 \mathrm{~cm}^{-1}\right)$ is quite different from that of the $\mathrm{N}_{2} \mathrm{O}$ species adsorbed onto $\mathrm{H}^{+} / \mathrm{ZSM}-5\left(2227 \mathrm{~cm}^{-1}\right)$. The evacuation of $\mathrm{N}_{2} \mathrm{O}$ at $298 \mathrm{~K}$ led to the complete disappearance of the band, indicating that $\mathrm{N}_{2} \mathrm{O}$ adsorbs reversibly onto $\mathrm{Ag}^{+}$ion. These results clearly suggest that the adsorption of the $\mathrm{N}_{2} \mathrm{O}$ onto the $\mathrm{Ag}^{+}$ion is weak, and the added $\mathrm{N}_{2} \mathrm{O}$ molecules easily interact with the $\mathrm{Ag}^{+}$ species on the ZSM-5 catalyst.

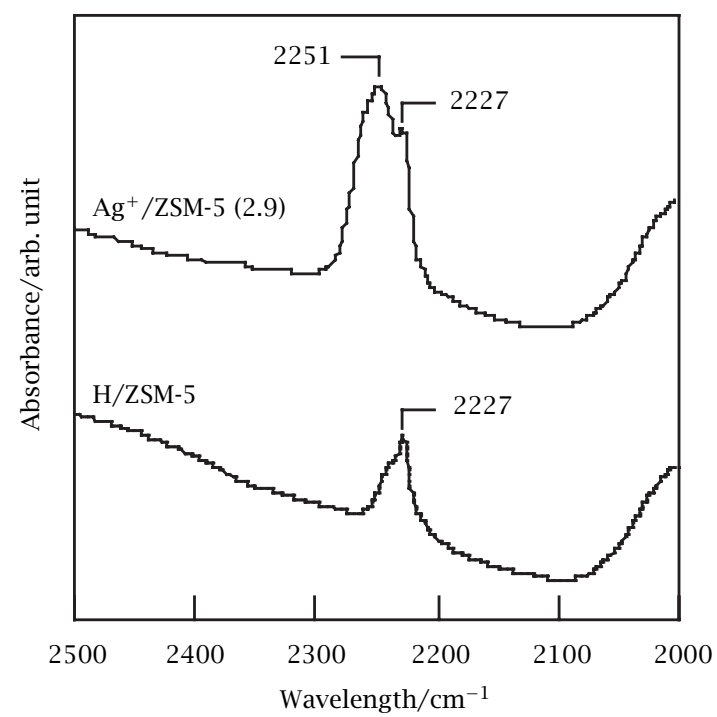

Figure 2. The FT-IR spectra of the $\mathrm{N}_{2} \mathrm{O}$ adsorbed on the $\mathrm{Ag}^{+} /$ZSM-5 (2.9) and $\mathrm{H}^{+} / Z S M-5$ catalysts at $298 \mathrm{~K}$. Added $\mathrm{N}_{2} \mathrm{O}: 1$ Torr.

As shown in Figure 3 , the $\mathrm{Ag}^{+} / \mathrm{ZSM}-5$ catalysts exhibit a photoluminescence at around $330 \mathrm{~nm}$ upon excitation at around $220 \mathrm{~nm}$. The absorption band and photoluminescence spectrum can be attributed to the electronic transition $\left(4 d^{10} \rightarrow 4 d^{9} 5 s^{1}\right)$ of the isolated

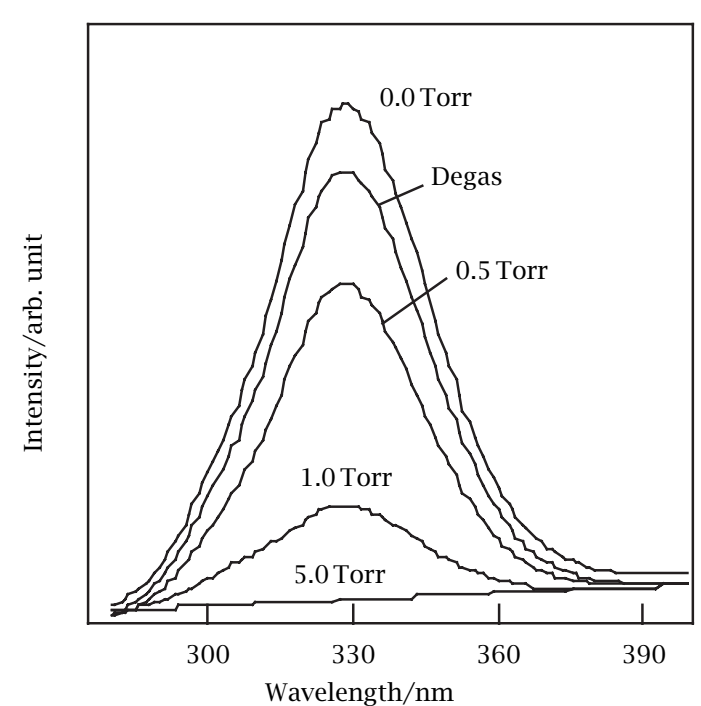

Figure 3. Photoluminescence spectrum of $\mathrm{Ag}^{+} / Z S M-5$ (2.9) and the effect of the addition of $\mathrm{N}_{2} \mathrm{O}$ on the $\mathrm{Ag}^{+} / Z S M-5$ (2.9) at $298 \mathrm{~K}$. Degas: after the degassing of $\mathrm{N}_{2} \mathrm{O}$ at $298 \mathrm{~K}$.

$\mathrm{Ag}^{+}$ion and its reverse radiative deactivation process $\left(4 d^{9} 5 s^{1} \rightarrow 4 d^{10}\right)$. As can also be seen in Figure 3, the addition of $\mathrm{N}_{2} \mathrm{O}$ onto $\mathrm{Ag}^{+} / \mathrm{ZSM}-5$ leads to an efficient quenching of the photoluminescence, while the degassing of $\mathrm{N}_{2} \mathrm{O}$ after the complete quenching (degas) leads to the recovery of the photoluminescence to its original intensity level. These results clearly suggest that almost all of the isolated $\mathrm{Ag}^{+}$ions can interact reversibly with $\mathrm{N}_{2} \mathrm{O}$ to form $\mathrm{Ag}^{+}-\mathrm{N}_{2} \mathrm{O}$ complexes.

Figure 4 shows the reaction profiles of the photocatalytic decomposition of $\mathrm{N}_{2} \mathrm{O}$ on $\mathrm{Ag}^{+} / \mathrm{ZSM}-5$ with

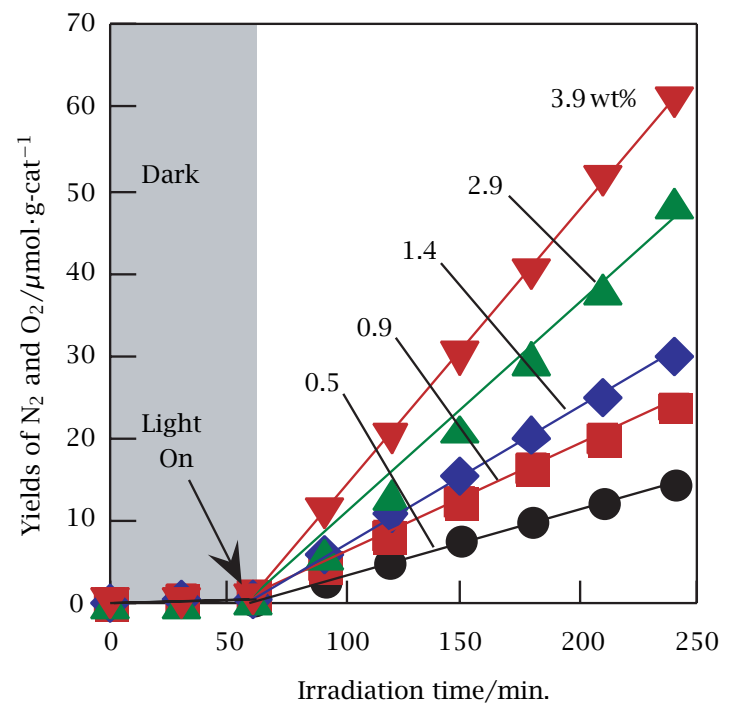

Figure 4. Reaction time profiles of the photocatalytic decomposition of $\mathrm{N}_{2} \mathrm{O}$ into $\mathrm{N}_{2}$ and $\mathrm{O}_{2}$ at $298 \mathrm{~K}$ on $\mathrm{Ag}^{+} / Z S M-5$ with different Ag loadings. 
different silver loadings at room temperature. UVirradiation of the $\mathrm{Ag}^{+} / \mathrm{ZSM}-5$ catalysts in the presence of $\mathrm{N}_{2} \mathrm{O}$ leads to the formation of $\mathrm{N}_{2}$ and $\mathrm{O}_{2}$. The yields of $\mathrm{N}_{2}$ and $\mathrm{O}_{2}$ increase with a good linearity against the UV-irradiation time, while under dark conditions these formations could not be detected, indicating that the reaction proceeds photocatalytically. The reaction rate for $\mathrm{N}_{2} \mathrm{O}$ decomposition also increases linearly against the amount of silver loading, suggesting that the isolated $\mathrm{Ag}^{+}$ions are an active species for this reaction. Furthermore, under UV-irradiation of the catalyst through an UV-25 filter $(\lambda>250 \mathrm{~nm})$, the photocatalytic decomposition of $\mathrm{N}_{2} \mathrm{O}$ proceeded at $4 \%$ of the rate of the reaction under the full arc of a high pressure mercury lamp. This indicates that the efficient UV-light for the reaction lies in wavelength regions of $200 \sim 250 \mathrm{~nm}$ where the absorption band of the $\mathrm{Ag}^{+}-\mathrm{N}_{2} \mathrm{O}$ complex exists. These results suggest that the photocatalytic decomposition of $\mathrm{N}_{2} \mathrm{O}$ on the isolated $\mathrm{Ag}^{+} / \mathrm{ZSM}-5$ proceeds through the photo-excitation of $\mathrm{Ag}^{+}-\mathrm{N}_{2} \mathrm{O}$ complexes.

From these findings, it was found that the isolated $\mathrm{Ag}^{+}$ion is the active species for the photocatalytic decomposition of $\mathrm{N}_{2} \mathrm{O}$, and the reaction proceeds through the photo-irradiation of the absorption band of the $\mathrm{Ag}^{+}-\mathrm{N}_{2} \mathrm{O}$ complex at around $220 \mathrm{~nm}$. A detailed study of the mechanisms behind the photocatalytic decomposition of $\mathrm{N}_{2} \mathrm{O}$ is presently underway and will be the subject of our future work.

\section{CONCLUSIONS}

$\mathrm{Ag}^{+} / \mathrm{ZSM}-5$ catalysts were prepared by an ion-exchange method. UV-irradiation of the $\mathrm{Ag}^{+} / \mathrm{ZSM}-5$ catalysts in the presence of $\mathrm{N}_{2} \mathrm{O}$ led to the photocatalytic decomposition of $\mathrm{N}_{2} \mathrm{O}$ into $\mathrm{N}_{2}$ and $\mathrm{O}_{2}$ at $298 \mathrm{~K}$. Investigations of the effective wavelength of the irradiated UVlight for the reaction as well as in-situ characterizations of the catalysts by means of UV-Vis, FT-IR and photoluminescence spectroscopies revealed that the photoexcitation of the $\mathrm{Ag}^{+}-\mathrm{N}_{2} \mathrm{O}$ complexes formed between $\mathrm{N}_{2} \mathrm{O}$ and the isolated $\mathrm{Ag}^{+}$ions exchanged within the zeolite cavities play a significant role in the reaction.

\section{REFERENCES}

[1] M. Anpo, M. Matsuoka, K. Hanou, H. Mishima, H. Yamashita, and H. H. Patterson, Coord. Chem. Rev. 171 (1998), 175.

[2] K. Ebitani, Y. Hirano, and A. Morikawa, J. Catal. 157 (1995), 262.

[3] M. Matsuoka, W. S. Ju, and M. Anpo, Chem. Lett. 6 (2000), 626.

[4] T. Miyadera, Appl. Catal. B 13 (1997), 157.

[5] M. Matsuoka, E. Matsuda, K. Tsuji, H. Yamashita, and M. Anpo, Chem. Lett. (1995), 375.

[6] M. Matsuoka, E. Matsuda, K. Tsuji, H. Yamashita, and M. Anpo, J. Mol. Catal. A 107 (1996), 399.

[7] M. Anpo, S. G. Zhang, H. Mishima, M. Matsuoka, and H. Yamashita, Catal. Today 39 (1997), 159.

[8] W. Zhang, M. Jia, J. Yu, T. Wu, H. Yahiro, and M. Iwamoto, Chem. Mater. 11 (1999), 920. 


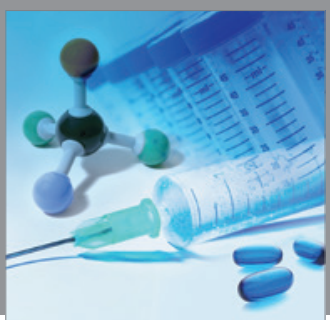

International Journal of

Medicinal Chemistry

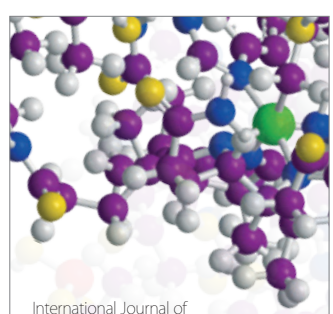

Carbohydrate Chemistry

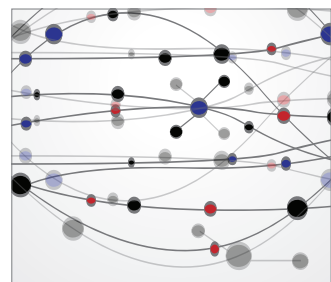

The Scientific World Journal
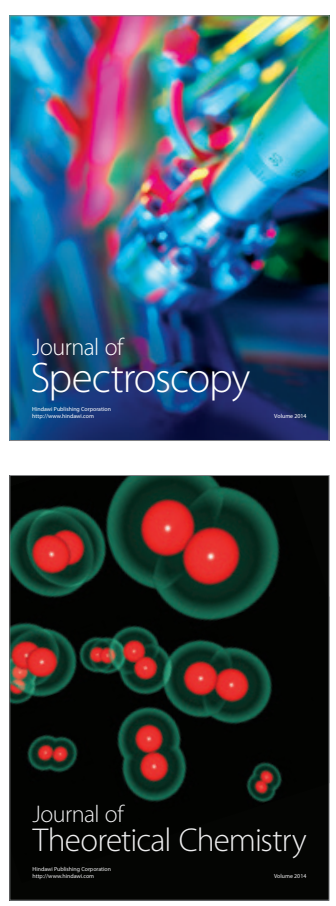
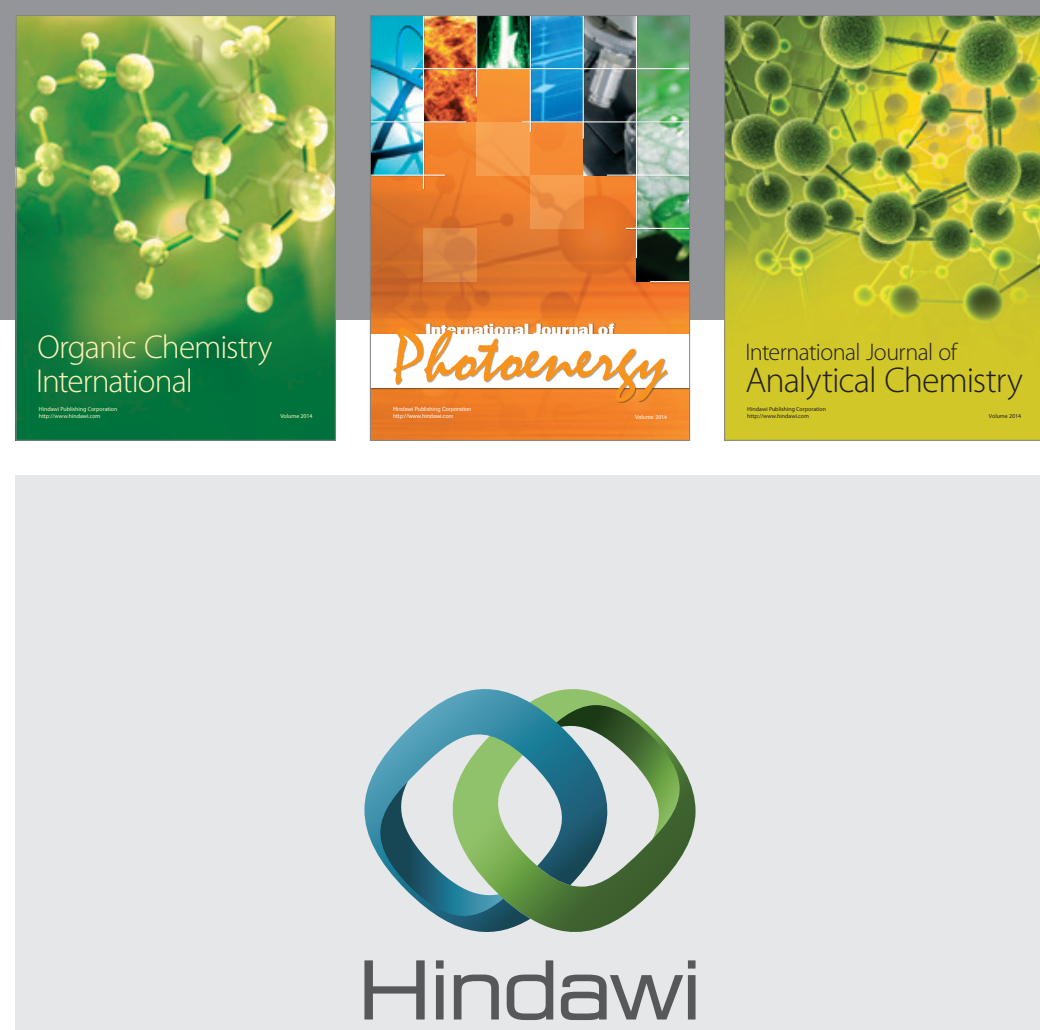

Submit your manuscripts at

http://www.hindawi.com
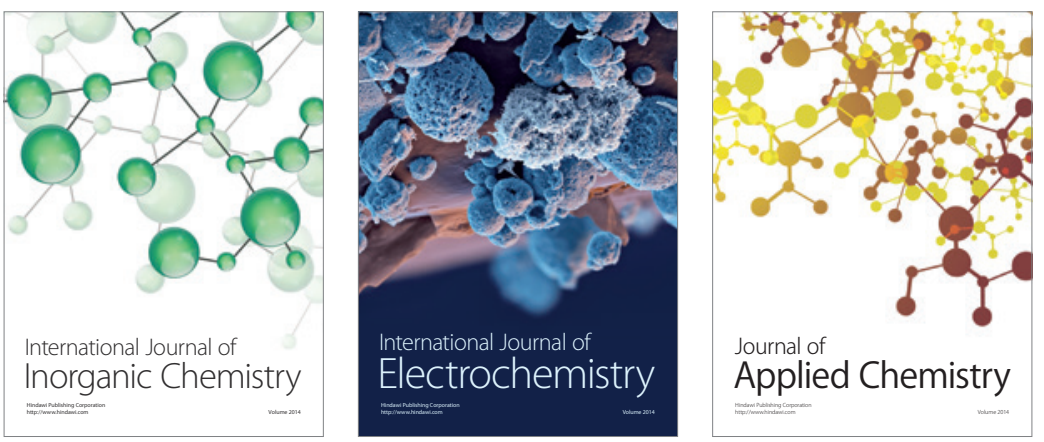

Journal of

Applied Chemistry
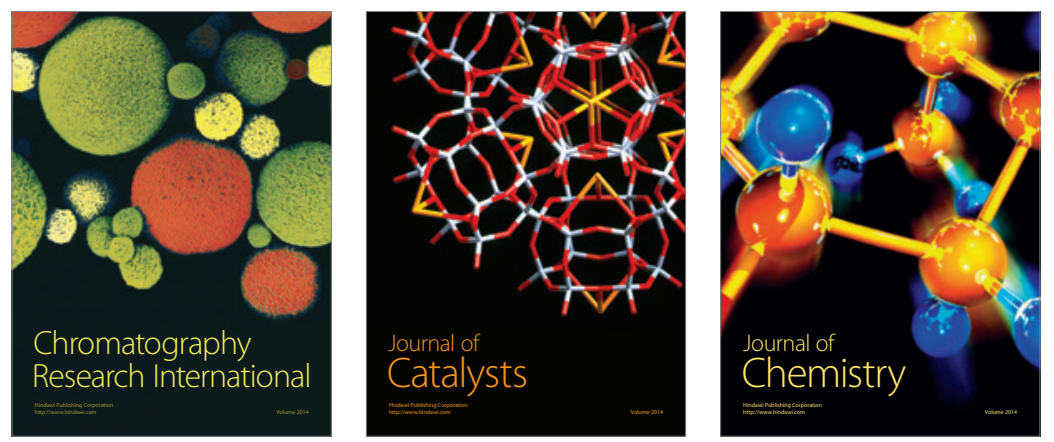
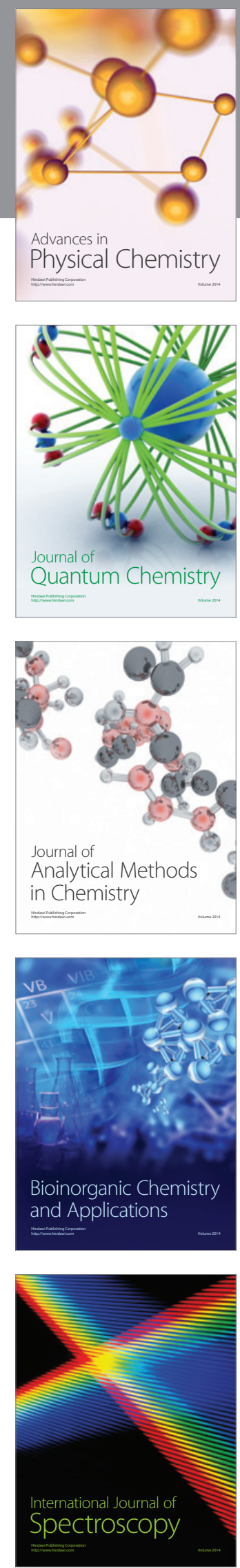